* Correspondence: Sergey Morozov, morozov@ belozersky.msu.ru Moscow, Russia; Moscow, Russia

\title{
ORIGIN OF THREE RELATED MOVEMENT GENE MODULES IN PLANT VIRUSES: EVOLUTIONARY RADIATIONS OF BENYVIRUS- LIKE RNA REPLICONS
}

22

${ }^{1}$ A. N. Belozersky Institute of Physico-Chemical Biology, Moscow State University,

${ }^{2}$ Department of Virology, Biological Faculty, Moscow State University, Moscow, Russia;

${ }^{3}$ Sechenov First Moscow State Medical University, Institute of Molecular Medicine, 


\section{ABSTRACT}

Previous studies have shown that the RNA genomes of some plant viruses encode two related genetic modules required for the virus movement over host body, containing 2 or 3 genes and named as triple gene block (TGB) and binary movement block (BMB). In this paper, we revealed a novel related movement gene module, called Tetra-Cistron Movement Block (TCMB). It was found to be encoded by virus-like transcriptome assemblies of moss Dicranum scoparium and Antarctic flowering plant Colobanthus quitensis. These TCMBs are encoded by second RNA components of the putative two-component viruses related to plant benyviruses. First, like RNA-2 of benyviruses, TCMB RNA-2 contains the 5'-terminal coat protein gene. Second, general organization of TCMB is very similar to TGB: it includes RNA helicase gene which is followed by two small overlapping cistrons encoding hydrophobic proteins with a distant sequence similarity to TGB2 and TGB3 genes. However, TCMB includes also forth 5'-terminal gene coding for protein with an obvious similarity to doublestranded RNA-binding proteins belonging to the DSRM_AtDRB-like superfamily. Finally, we suggest the proposed involvement of replicative beny-like helicases in evolution of the BMB and TCMB movement genetic modules.

Keywords: RNA genome, plant virus, movement gene module, benyviruses, evolution, RNA helicase, plants 


\section{INTRODUCTION}

All triple gene block (TGB)-containing viruses are represented by a large variety of plant RNA viruses within the orders Martellivirales (family Virgaviridae), Tymovirales (familes Alphaflexiviridae and Betaflexiviridae) and Hepelivirales (family Benyviridae). They have a positive-sense, single-stranded genome consisting of one to four RNA segments (Morozov and Solovyev, 2003; Verchot-Lubicz et al., 2010; Koonin et al., 2020). The TGBencoded movement proteins, referred to as TGB1, TGB2 and TGB3, perform directed transport of viral genomes to and through plasmodesmata (PD) into adjacent non-infected cells. TGB1 contains protein domain of RNA helicase of superfamily 1 (SF1), whereas TGB2 and TGB3 are the small membrane-associated proteins and contain highly hydrophobic amino acid segments (Verchot-Lubicz et al., 2010). Recently, binary movement block (BMB), which is related to TGB, was found in kitaviruses (family Kitaviridae, order Martellivirales). This gene module includes only two genes (BMB1 and BMB2). Although pairs of BMB1/TGB1 and BMB2/TGB2 proteins are quite similar in structural, functional and phylogenetic aspects (Morozov and Solovyev, 2015, 2020; Solovyev and Morozov, 2017; Lazareva et al., 2017; 2021), BMB gene module lacks analog of TGB3. Importantly, recent data showed that some viruses from genera Potexvirus and Carlavirus encode no TGB3 proteins, despite the fact that TGB1 and TGB2 proteins of these viruses are significantly similar to those of potexvirus-like TGBs (Morozov and Solovyev, 2015). These observations support the hypothesis that the TGB3 gene could be a less essential component (an accessory cistron) of transport gene module. Conceivably, TGB3 could be evolved as an additional cistron if BMB was the first transport module of this type appeared in virus genomes or, alternatively, could be eliminated during evolution of earliest TGB-related movement modules (Morozov and Solovyev, 2015, 2020; Solovyev and Morozov, 2017). Taking into account these considerations, identification of new TGB/BMB-like gene modules in lower land plants could shed a new light on the early steps of TGB/BMB evolution. So far, only a single TGB-containing virus-like RNA assembly has been revealed in non-seed plants, namely, bird's-nest fern Asplenium nidus. This fern virus shows gene arrangements and sequence similarities indicating its close relatedness to benyviruses (Morozov and Solovyev, 2015).

In our recent paper, we draw attention to partial transcriptome assemblies in the Antarctic flowering plant Colobanthus quitensis, where a probable evolutionary early variant of TGB was found (Cq-TGB) (Solovyev and Morozov, 2017). Importantly, the Cq-TGB1 protein sequence is more similar to BMB1 in comparison with TGB1 proteins (Fig. 1). 
109 Moreover, the central hydrophilic region of Cq-TGB3 protein located between two

110 transmembrane sequence segments shows clear amino acid sequence similarity to the Cq-

111 TGB2 protein and exhibits conservation of most amino acid residues invariant in other TGB2

112 proteins (Solovyev and Morozov, 2017). These data suggest that Cq-TGB could arise from a

113 BMB-like module by duplication of hydrophobic protein gene. Importantly, the Antarctica

114 coast flora was isolated from the rest of the world for approximately 20 million years

115 (Cantrill and Poole, 2013). This fact provided a reasonable basis for considering Cq-TGB as

116 one of the ancient movement gene modules and further prompted us to search available

117 sequence data to find more viral gene blocks related to TGB/BMB modules in transcriptomes

118 of non-seed plants and extant land plants.

119 In this paper, we reported new virus-like RNA assemblies (VLRAs) in the NCBI TSA

120 and SRA databases and identified a novel plant virus movement gene module in the

121 transcriptome samples of two wild plant species. This gene module could be classified as

122 structurally and evolutionary related to BMB and TGB. Additionally, we presented new data

123 supporting an idea that the movement gene modules related to TGB could initially originate

124 in the benyvirus-like replicons.

NOVEL MOVEMENT GENE MODULE IN THE VIRUS-RELATED PLANT TRANSCRIPTOMES: TETRA-CISTRON MOVEMENT BLOCK

We undertook a systematic analysis of RNA-seq datasets from Viridiplantae available in the NCBI open-access TSA and SRA in the end of November, 2021. Our TBLASTn search of plant TSA data collection, using Cq-TGB encoded helicase (accession GCIB01126289) as a query, resulted in the identification of a new partial VLRA (accession HANF01089872) in moss Dicranum scoparium (family Dicranaceae, order Dicranales) encoding protein with obvious similarity to Cq-TGB1 (Fig. 1). Using transcriptome sequencing data for the D. scoparium SRA experiment (ERX3824048), we further assembled a nearly full-length sequence of the contig (Ds-VLRA2) comprised 3,996 nt excluding the poly(A) tail. The open reading frame (ORF) prediction at ExPASy (ESTscan) showed that the contig contains six ORFs flanked by a 5' untranslated region (5' UTR, at least $183 \mathrm{nt}$ ) and a 3' UTR (165 nt) (Fig 2A). The resulting D. scoparium VLRA exhibits a gene content and arrangement quite similar to that in RNA 2 of benyviruses (Fig. 2B) (Saito et al., 1996).

139 Indeed, this RNA encodes the 5'-terminal coat protein (CP) gene (ORF1) and TGB-like 140 module (Fig. 2A). Although the CP of Ds-VLRA2 (220 aa in length) has only marginal 141 amino acid similarity with the members of genus Benyvus, it shows obvious similarity to 
other tobamovirus-like CPs, namely, the tobacco rattle virus CP (genus Tobravirus; family Virgaviridae) (ABE27877, 31\% identity, E-value 1e-11), and the pea early-browning virus CP (genus Tobravirus; family Virgaviridae) (CAA07067, 29\% identity, E-value 2e-11).

The ORF2 and ORF3 of Ds-VLRA2 encode proteins of 301 aa and 120 aa residues in length, respectively (Fig.2A). BLASTn and BLASTx analyses showed that ORF2 protein has no significant sequence homology with known virus polypeptides (data not shown). The NCBI Conserved Domain Database (CDD) analysis identified that the ORF2 protein could contain a possible domain related to the SMC superfamily (Accession No. cl34174, E-value 6.56e-03). The SMC (structural maintenance of chromosomes) domain is found in the proteins that bind DNA and act in organizing and segregating chromosomes (Lehmann, 2005). Additional protein domain analyses using ExPASy (ProtScale) software predicted a coiled-coil motif located at amino acid positions 136-185 and two highly hydrophobic sequences positioned at residues 45-63 and 279-299 in ORF2 protein (Fig. 3).

The NCBI CDD analysis also identified a possible domain in the ORF3 protein, corresponding to the DSRM_AtDRB-like superfamily (Accession No. c100054, E-value 1.6e03). Therefore, the Ds-VLRA2 ORF3 protein was named viral DRB (vDRB). The DSRM protein domain superfamily is a well-known protein structural motif of 65-70 aa in length that adopts an alpha-beta-beta-beta-alpha fold and binds double-stranded RNAs (dsRNAs) of various origin and structure. This family includes a group of Arabidopsis thaliana doublestranded RNA-binding proteins termed AtDRB1-AtDRB5. Members of this group usually contain two DSRM domains. They bind dsRNA and are involved in RNA-mediated silencing (Han et al., 2004; Eamens et al., 2012) and/or dsRNA-triggered immunity against viruses (Fátyol et al., 2020). The vDRB protein encoded by Ds-VLRA2 contains a single DSRM showing conservation of key residues specific for DSRM_AtDRB-like proteins (Fig. 4). Interestingly, AtDRB-like proteins are encoded not only by flowering plants but also representatives of lower vascular plants (Lycopodiopsida), mosses (Bryophyta) and liverworts (Marchantiophyta). Moreover, these proteins can be revealed in present-day

169 Charophyte algae (members of Zygnemophyceae and Charophyceae families), which are assumed to be the closest relatives of land plants descendent of the organisms that took part in initial colonization of terrestrial habitats (Fig. 4). Importantly, the Ds-VLRA2 vDRB protein, unlike AtDRB1-AtDRB5, contains a hydrophobic transmembrane segment at the Nterminus (Fig. 5).

The ORF4 in Ds-VLRA2 overlaps the ORF3 by 60 nucleotides (Fig. 2A) and encodes protein of 361 residues containing motifs characteristic for helicases of SF1 superfamily and 
176

177

178

179

180

181

182

183

184

185

186

187

188

189

190

191

192

193

194

195

196

197

198

199

200

201

202

203

204

205

206

207

208

209

showing obvious similarity to BMB1 helicases (Fig. 1). ORF4 is followed by overlapping ORF5 and ORF6 (Fig. 2A), which code for small hydrophobic proteins with two putative transmembrane domains and central hydrophilic region related to TGB2/BMB2 proteins (Fig. 6). Protein sequence similarity of the encoded proteins and general organization of the gene block represented by ORFs 4-6 of Ds-VLRA2 resembles TGB and related Cq-TGB-like module (accession GCIB01126289).

Taking into account the similarity of Ds-VLRA2 TGB and Cq-TGB, we further analyzed whether the previously assembled $C$. quitensis TGB-containing VLRA was incomplete and could be extended into the 5'-terminus direction. Our de novo assembly of transcriptome sequencing data for $C$. quitensis SRA experiment (SRX814890) resulted in the probable full-length contig (Cq-VLRA2) of 4,718 nt in length excluding the poly(A) tail. The resulting sequence was confirmed using incomplete contigs from TSA database (GCIB01147888, GCIB01142942, GCIB01133924 and GCIB01126289). The ORF prediction at ExPASy showed that this contig contains seven ORFs flanked by a 5'untranslated region (5'-UTR, at least $259 \mathrm{nt}$ ) and a 3'-UTR (213 nt). The 5'-terminal ORF1 encodes a capsid protein (164 aa in length) (Fig 2A) showing similarity to the wheat stripe mosaic virus CP (genus Benyvirus) (YP009553316, 27\% identity, E-value 1e-04), and the sorghum chlorotic spot virus CP (genus Furovirus; family Virgaviridae) (NP659022, 29\% identity, E-value 3e-04). The next ORF2 represents read-through domain of CP fusion protein as it was reported for benyviruses (Fig. 2B) (Saito et al., 1996). Among three described types of read-through nucleotide signatures, ORFs1/2 contain the type I motif containing a UAG codon, which is followed by the consensus motif CARYYA (where $\mathrm{R}$ is a purine and $\mathrm{Y}$ is a pyrimidine). This mechanism of translation is also used in tobamovirus replicase genes (Firth and Brierley, 2012; Miras et al., 2017).

ORF2 is followed by an intergenic region of 73 nucleotides in length and an ORF3, which codes for a small protein with the charged $\mathrm{N}$-terminal half and cysteine-rich $\mathrm{C}$ terminal region (Fig. 2A, Fig. 7). This cysteine-rich protein (CRP) shows no sequence similarity to the RNA2-encoded benyvirus CRP (Fig. 2B), and its cysteine-rich region is marginally similar to double zinc finger motif-containing module of FYVE domain involved in mRNA transport to endosomes (Pohlmann et al., 2015).

The NCBI BLAST analysis showed that Cq-VLRA2 ORF4 protein is quite similar to Ds-ORF3 (vDRB) protein and contains single DSRM with signatures specific for DSRM_AtDRB-like proteins (Fig. 4) and the N-terminal hydrophobic segment (Fig. 5). CqORF4 is followed by an overlapping ORF5 encoding protein of 355 amino acids in length 
210 (Fig. 2A). The Cq-ORF5 protein (earlier named Cq-TGB1, see above) possesses motifs

211 characteristic for helicases of SF1 superfamily and shows significant similarity to Ds-ORF4

212 protein (Ds-TGB1) and BMB1 helicases (Fig. 1). Like Ds-VLRA2, Cq-ORF4 is followed by

213 overlapping ORFs 5 and 6 (Fig. 2) encoding small hydrophobic proteins with two putative

214 transmembrane domains and central hydrophilic region related to Ds-ORF5/6 proteins (Fig.

215 6).

A general view on the organization of Ds-VLRA2 and Cq-VLRA2 strongly suggests two conclusions: 1) Both virus-like RNAs have considerable similarity to the benyvirus

218 TGB-containing RNA2. Indeed, RNA2 of the type benyvirus Beet necrotic yellow vein virus

219 (BNYVV) has six ORFs, namely, the CP gene terminated by a leaky stop codon, the CP read-

220 through protein gene, the TGB and the cistron coding for a cysteine-rich protein having a silencing suppressor activity (Fig. 2B) (Saito et al., 1996; Chiba et al., 2013); 2) These RNAs include a conserved module of four overlapping genes, which is proposed to be named "Tetra-Cistron Movement Block" (TCMB). In comparison with the TGB and BMB modules, TCMB includes an additional 5'-terminal ORF, which overlaps the downstream gene and codes for the vDRB protein with a novel, previously undescribed for virus-encoded proteins, dsRNA-binding activity. Importantly, the cellular DRBs were shown to be incorporated into virus-specific replication membrane compartments (Barton et al., 2017; Incarbone et al., 2021), the structures often located at the PD orifice and involved in virus cell-to-cell movement (Tilsner et al., 2013). Similarly, the related hydrophobic vDRB proteins could be proposed to work in concert with other TCMB proteins to take part in viral dsRNA delivery to and/or retaining in PD-associated ER membrane-derived replicative compartments (Tilsner et al., 2013; Lazareva et al., 2021) and, thus, participate in virus cell-to-cell movement.

\section{PROPOSED GENERAL ORGANIZATION OF TCMB-CONTAINING PLANT}

\section{VIRUS GENOMES}

Assuming similarity of Ds-VLRA2 and Cq-VLRA2 to benyvirus RNA2 (Fig. 2) in gene organization, we performed search of the NCBI Dicranum scoparium TSA database in an attempt to find Ds-RNA1 expecting to code for virus replicase as in the case of BNYVV. As an initial query, we used 150 amino acid-long segment of BNYVV replicase (GDD domain). BLAST search revealed a single TSA contig (HANF01090670) of 305 nucleotdes in length which codes for a protein segment containing a GDD motif typical for RNAdependent RNA polymerase ( $\mathrm{RdRp}$ ) domain and having more than $60 \%$ protein identity to

242 BNYVV replicase protein (data not shown). To assemble the expected Ds-RNA1, 
transcriptome sequencing data for D. scoparium SRA experiment ERX3824048 linked to the TSA project were used. The assembled full-length sequence of the contig comprised 6,624 nt, excluding the poly(A) tail. ORF prediction showed that the contig contains a single cistron encoding viral replicase flanked by a 5'-UTR (at least $78 \mathrm{nt}$ ) and a 3' UTR (237 nt) (Fig. 8A). Importantly, pairwise BLASTN analysis of the 3'-untranslated regions from Ds-VLRA1 and Ds-VLRA2 indicated a significant degree of sequence conservation among them and strongly suggested that both moss VLRAs are indeed the two components of a single virus genome (Fig. 8B).

ORF1 protein of Ds-VLRA1 contains four conserved domains: a viral methyltransferase domain (MTR, pfam01660, amino acid positions 440-625, E-value 2.58e06); a viral helicase 1 domain (HEL, pfam01443, amino acid positions 939-1179, E-value 4.70-22); papain-like proteinase domain (PROT, pfam05415, positions 1333-1408, E-value 6.97-06), and RdRp core motif (pfam00978, amino acid positions 1698-2045, E-value 2.42e14) (Fig. 8A). The MTR domain is known to be conserved in a wide range of single-stranded RNA viruses, including orders Martellivirales, Tymovirales and Hepelivirales (Rozanov et al., 1992). All replicases in the members of these orders also encode HEL and RdRp domains containing typical motifs (Koonin and Dolja, 1993) conserved also in the ORF1 protein of Ds-VLRA1. Although the protease domain is not common for the above-mentioned replicases, Ds-VLRA1 encodes a protein domain with similarity to benyvirus protease (Fig. $8 \mathrm{~A})$, which is conserved in most benyviruses and required to produce mature replicase proteins by proteolytic self-cleavage (Rodamilans et al., 2018).

We further used encoded amino acid and nucleotide sequences of Ds-VLRA1 as queries for searches of $C$. quitensis SRA data (SRX814890) in order to assemble a Cq-RNA1 complete nucleotide sequence. However, only a rather short nucleotide sequence encoding a part of RdRp domain (including the GDD signature), which showed significant similarity to Ds-VLRA1 protein and moderate similarity to benyvirus replicases, has been assembled (Fig. 9). AND TCMB

An important clue to the pathways of evolutionary origin of TGB, BMB and TCMB, to our mind, is provided by phylogenetic analysis of their encoded helicases. Evidently, BMB and TCMB helicases form a common branch which is closer to benyvirus TGB helicases and less similar to potex- and hordei-like TGB helicases (Fig. 1). Moreover, BMB and TCMB 
helicases show more sequence identity to beny-like replication helicases than to potex- and hordei-like TGB helicases (Morozov and Solovyev, 2015). Therefore, it can be suggested that a starting event in the evolutionary emergence of BMB- and TCMB could be duplication and autonomization of the replicative helicase domain occurred due to template switching during the virus genome replication along with probable non-replicative joining of RNA fragments (Bujarsky, 2013). Such RNA-RNA recombination likely resulted in the formation of the earliest monopartite and/or multipartite beny-like replicons with an autonomized copy of SF1 helicase. Recombination-dependent scenarios for evolutionary radiation have been also proposed for viruses of the family Hepeviridae (Kelly et al., 2016), which, together with benyviruses and tetraviruses (Dorrington et al., 2020), comprise the order Hepelivirales (Koonin et al., 2020). Taking into account the fact that the currently revealed TCMBcontaining viruses infect primitive land plant (moss) (this paper) or the geographically longterm isolated flowering plant C. quitensis (Solovyev and Morozov, 2017), TCMB might be considered as an evolutionary old movement gene module originated in benyvirus-like replicons.

\section{ORIGINATION OF HYDROPHOBIC PROTEIN GENES IN MOVEMENT}

\section{GENETIC MODULES}

As it was suggested above, possible starting event in evolution of BMB- and TCMBcontaining viruses was the formation of the beny-like replicons with an autonomized (duplicated) copy of beny-like SF1 replicative helicase. However, phenomenon of origination and acquisition of hydrophobic protein genes in different types of movement gene modules is generally obscure (Morozov and Solovyev, 2015; 2020). In this study, we found that among monopartite plant beny-like viruses, in addition to BMB-containing replicons, many VLRAs and viruses contain one or two small ORFs, which are located downstream of the replicase gene and encode small "orphan" proteins with one or two hydrophobic segments (Fig. 9 and Fig. 10) (Solovyev and Morozov, 2017).

We hypothesize that these hydrophobic "orphan" protein ORFs have originated due to recombination of viral RNAs with host transcripts containing de novo emerged ORFs. Indeed, it was proposed that novel eukaryotic "orphan" protein-coding genes can arise de novo in non-coding sequences, which, thus, may serve as a continuous reservoir of variable novel polypeptides serving as a raw material for natural selection (Vakirlis et al., 2020). Moreover, evolution of non-coding thymine-rich sequences can result in preferable emergence of ORFs encoding proteins with hydrophobic domains (Vakirlis et al., 2020; 
311 Fesenko et al., 2021). These findings allowed our colleagues to propose a novel evolutionary

312 model suggesting that ORFs for small membrane-bound polypeptides emerging de novo in

313 basal land plants could be a preferential subject of adaptive evolution because of escape of

314 their encoded proteins from degradation or other deleterious interactions in the membrane

315 environment (Fesenko et al., 2021). Therefore, viruses similar to the above-mentioned

316 monopartite beny-like replicons, which might be produced through recombination with

317 mRNAs carrying such ORFs for membrane polypeptides, can be proposed to serve as sources

318 of ancestral membrane protein genes for recombination-dependent evolution TCMB- and

319 BMB-like genetic modules and also some other movement genetic modules described for

320 plant viruses (Morozov and Solovyev, 2020).

\section{EVOLUTIONARY RADIATION OF BENYVIRUS-LIKE RNA REPLICONS}

Assuming the proposed involvement of replicative beny-like helicase in evolution of the above-mentioned movement genetic modules, it is tempting to speculate on the global evolution of beny-like replication proteins. Generally, a phylogenetic tree of selected benylike RdRp domains (Fig. 9) showed three main branches including (i) a basal branch composed of closely related RNA viruses from fresh-water species of algal genus Chara found in Australia and Canada (Gibbs et al., 2011; Vlok et al., 2019); (ii) a branch of benyviruses (Niehl et al., 2020), plant bipartite viruses with TCMB (this study) and related monopartite plant beny-like viruses and VLRAs; (iii) a mixed branch including fungal and arthropod viruses, as well as VLRAs from red algae. Indeed, recent advances in sequencing benyvirus-like RNA replicons revealed their multiple hosts not only in plants but also among arthropods (particularly, Bemisia tabaci beny-like virus 6 - MW256699; Bemisia tabaci benylike virus 4 - MW256697; Hubei Beny-like virus 1 - MK231108; Diabrotica undecimpunctata virus 2 - MN646771) and fungi (particularly, Erysiphe necator associated beny-like virus 1 MN617775; Rhizoctonia solani beny-like virus 1 - MK507778; Sclerotium rolfsii beny-like virus 1 - MH766487) (Fig. 9) (Shi et al., 2016; Zhu et al., 2018; Picarelli et al., 2019; Gilbert et al., 2019; Liu et al., 2020).

Significantly, among monopartite Viridiplantae viruses, the beny-like replicase is encoded by two viruses with an unusual gene organization, namely, beny-like Chara virus

341 (Vlok et al., 2019) and goji berry chlorosis virus (GBCV) (Kwon et al., 2018). It is known

342 that charophyte algae are considered as the ancestors of land plants, and Chara viruses may

343 be evolutionarily related to ancestor virus species that infected first plants colonizing 344 terrestrial habitats (Vlok et al., 2019). Interestingly, beny-like Chara viruses are distributed 
around the globe, since in addition to species found in Australia and North America we revealed closely related viral RNA metagenomic sequences in the NCBI Sequence Read Archive (SRX8007769), BioProject accession PRJNA615325 (data not shown). These data were derived from samples of fish gills collected from Qinghai Lake in Tibet. The largest encoded protein of these monopartite viruses shows the relationship with RNA polymerases of benyviruses (Fig. 9), while the capsid protein is distantly related to the tobamovirus CP (Gibbs et al., 2011; Vlok et al., 2019). Two additional open reading frames (ORFs) code for an RNA helicase and a protein of unknown function. Importantly, this non-replicative "accessory" helicase is related to helicases of SF-2 superfamily in contrast to "accessory" TGB1 helicases belonging to SF-1 (Vlok et al., 2019). It is clear the replicase and tobamolike $\mathrm{CP}$ genes belong to different lineages of the alphaviruses, orders Hepelivirales and Martellivirales, respectively, whereas the "accessory" helicase to replicative helicase of viruses belonging to order Amarillovirales (Vlok et al., 2019).

The GBCV genome encodes six polypeptides. Strikingly, the replicase (ORF1) is more similar to benyvirus-like replicases, whereas coat protein (ORF2) is more closely related tobamovirus-like CPs (Solovyev and Makarov, 2016) and ORF5 encodes a movement protein related to the tobamovirus-like MP. Unusual genome organization suggests that GBCV may represent a recombinant between the viruses from families Benyviridae and Virgaviridae (Kwon et al., 2018). This evolutionary episode also suggests a realistic possible pathway for advanced evolution of TGB, where the horizontal gene transfer of this gene module from beny-like RNA replicons could occur to ancestral replicons belonging to viruses belonging to orders Martellivirales and Tymovirales and initiate the evolution of potex-like and hordei-like TGBs.

Recent studies suggest not only ways of radiation of genome organization for benylike replicons but also approximate gene divergence dates. It was shown that the estimates of gene divergence dates for the RdRp and CP proteins from Virgaviridae and Benyviridae are quite different. Generally, wide distribution of tobamo-like CP genes (Solovyev and Makarov, 2016) in viruses of orders Hepelivirales and Martellivirales strongly suggests significant role of horizontal gene transfer in evolutionary radiation of these genes (Shi et al., 2016). The divergence of the charavirus CP with that of tobamoviruses (family Virgaviridae) was estimated to be 212 million years ago (mya) (Vlok et al., 2019). On the other hand, time for divergence between charavirus/benyvirus RdRp (order Hepelivirales) and virga-like

377 RdRp genes (order Martellivirales) was estimated to be 900 mya (Vlok et al., 2019). So, it seems that benyvirus-like replicases started their evolutionary radiations in late Precambrian, 
i.e. perhaps even before the chlorophyte-charophyte split likely occurred 850-1100 million years ago (Del Cortona et al., 2020; Strassert et al., 2021). In this respect, it is important that the red algae (Rhodophyta) are most ancient in the kingdom Plantae (Archaeplastida) (https://www.algaebase.org/browse/ taxonomy/), and an origin of multicellular red algae is expected around 1000-1600 mya (Schön et al., 2021; Carlisle et al., 2021; Strassert et al., 2021). So, the divergence between replication proteins of viruses in orders Hepelivirales and Martellivirales could occur in marine red algae species. In support for the proposed role of Rhodophyta as a host for common ancestors of Hepelivirales and Martellivirales, it was found that the both types of virus replicons can be found in modern red algae hosts (Fig. 11).

\section{EXPERIMENTAL}

Virus nucleotide and protein sequences were collected from the NCBI database. Assembled viral genomes were mainly extracted from NCBI database. The sequence comparisons were carried out using the BLAST algorithm (BLASTn and BLASTp) at the National Center for Biotechnology Information (NCBI). Open reading frames (ORFs) were identified using the NCBI ORF Finder program (http://www.bioinformatics.org/sms2/ orf_find.html). Gene translation and prediction of deduced proteins were performed using ExPASy (http://web.expasy.org/translate/). Conserved motif searches were conducted CDD (http://www.ncbi.nlm.nih.gov/Structure/cdd/wrpsb.cgi) databases. Coiled-coil protein regions were predicted using Waggawagga software (https://waggawagga.motorprotein.de/) (Simm et al., 2021).

To assemble the full-length plant VLRAs, transcriptome sequencing data for $D$. scoparium and $C$. quitensis SRA experiments linked to the TSA projects were downloaded using fastq-dump tool of NCBI SRA Toolkit 2.9.0. (http://ncbi.github.io/sra-tools/). Reads quality was checked with FastQC (https://www.bioinformatics.babraham.ac.uk/ projects/fastqc/). De novo assembly of VLRAs coding for TCMB modules was carried out using SPAdes 3.12.0 (Bankevich et al., 2012) in "RNA mode".

Phylogenetic analysis was performed with "Phylogeny.fr" (a free, simple to use web service dedicated to reconstructing and analysis of phylogenetic relationships between molecular sequences) by constructing maximum likelihood phylogenetic trees (http://www.phylogeny.fr/simple_phylogeny.cgi). Bootstrap percentages received from 1,000 replications were used. 


\section{ACKNOWLEDGMENTS}

414 The authors are grateful for the funding received by the Russian Foundation for Basic

415 Research (grant 20-04-00456).

416

\section{AUTHOR CONTRIBUTIONS}

418 SM collected and analyzed the data, authored drafts of the paper;

419 AS authored drafts of the paper, prepared figures, reviewed the final draft.

420

\section{CONFLICT OF INTEREST STATEMENT}

The authors declare that the research was conducted in the absence of any commercial or financial relationships that could be construed as a potential conflict of interest.

\section{DATA AVAILABILITY STATEMENT}

The datasets presented in this study can be found in online repositories. The names of the repository/repositories and accession number(s) mentioned in this paper can be found at: https://www.ncbi.nlm.nih.gov/.

\section{REFERENCES}

Bankevich A., Nurk S., Antipov D., Gurevich A.A., Dvorkin M., Kulikov A.S., Lesin V.M., Nikolenko S.I., Pham S., Prjibelski A.D., Pyshkin A.V., Sirotkin A.V., Vyahhi N., Tesler G., Alekseyev M.A., Pevzner P.A. (2012). SPAdes: a new genome assembly algorithm and its applications to single-cell sequencing. J. Comput. Biol. 19, 455-477.

435

Barton D.A., Roovers E. F., Gouil Q., da Fonseca G. C., Reis R. S., Jackson C., Overall R. dsRNA Binding Proteins Upon Viral Infection. Mol. Plant Microbe Interact. 30, 435-443. doi: 10.1094/MPMI-02-17-0035-R.

443 Cantrill D. J., Poole I. (2013). The Vegetation of Antarctica through Geological Time. New 444 York, NY: Cambridge University Press, 466.

445 Carlisle E. M., Jobbins M., Pankhania V., Cunningham J. A., Donoghue P. C. J. (2021).

446 Experimental taphonomy of organelles and the fossil record of early eukaryote evolution. Sci. $447 \quad A d v .7$, eabe9487. doi: 10.1126/sciadv.abe9487.

448 Chiba S., Hleibieh K., Delbianco A., Klein E., Ratti C., Ziegler-Graff V., Bouzoubaa S., 449 Gilmer D. (2013). The benyvirus RNA silencing suppressor is essential for long-distance 450 movement, requires both zinc-finger and NoLS basic residues but not a nucleolar localization 
for its silencing-suppression activity. Mol. Plant Microbe Interact. 26, 168-181. doi: 10.1094/MPMI-06-12-0142-R.

Del Cortona A., Jackson C. J., Bucchini F., Van Bel M., D'hondt S., Škaloud P., Delwiche C. F., Knoll A. H., Raven J. A., Verbruggen H., Vandepoele K., De Clerck O., Leliaert F. (2020). Neoproterozoic origin and multiple transitions to macroscopic growth in green seaweeds. Proc. Natl. Acad. Sci. U S A 117, 2551-2559. doi: 10.1073/pnas.1910060117.

Dorrington R. A., Jiwaji M., Awando J. A., Bruyn M. M. (2020). Advances in Tetravirus Research: New Insight Into the Infectious Virus Lifecycle and an Expanding Host Range. Curr. Issues Mol. Biol. 34, 145-162. doi: 10.21775/cimb.034.145.

Eamens A. L., Kim K. W., Waterhouse P. M. (2012). DRB2, DRB3 and DRB5 function in a non-canonical microRNA pathway in Arabidopsis thaliana. Plant Signal. Behav. 7, 12241229. doi: $10.4161 / \mathrm{psb} .21518$.

Fátyol K., Fekete K. A, Ludman M. (2020). Double-stranded-RNA-binding protein 2 participates in antiviral defense. J. Virol. 94, e00017-20. doi: 10.1128/JVI.00017-20.

Fesenko I., Shabalina S. A., Mamaeva A., Knyazev A., Glushkevich A., Lyapina I., Ziganshin R., Kovalchuk S., Kharlampieva D., Lazarev V., Taliansky M., Koonin E. V. (2021). A vast pool of lineage-specific microproteins encoded by long non-coding RNAs in plants. Nucleic Acids Res. 49, 10328-10346. doi: 10.1093/nar/gkab816.

Firth A. E., and Brierley, I. (2012). Non-canonical translation in RNA viruses. J. Gen. Virol. 93, 1385-1409. doi: 10.1099/vir.0.042499-0.

Gibbs A. J., Torronen M., Mackenzie A. M., Wood J. T., II, Armstrong J. S., Kondo H., et al. (2011). The enigmatic genome of Chara australis virus. J. Gen. Virol. 92, 2679-2690. doi: 10.1099/vir.0.033852-0.

Gilbert K. B., Holcomb E. E., Allscheid R.L., Carrington, J. C. (2019) Hiding in plain sight: New virus genomes discovered via a systematic analysis of fungal public transcriptomes. PLoS One 14, e0219207. doi: 10.1371/journal.pone.0219207.

Han M. H., Goud S., Song L., Fedoroff N. (2004). The Arabidopsis double-stranded RNAbinding protein HYL1 plays a role in microRNA-mediated gene regulation. Proc. Natl. Acad. Sci. USA 101, 1093-1098. doi: 10.1073/pnas.0307969100.

Incarbone M., Clavel M., Monsion B., Kuhn L., Scheer H., Vantard É., Poignavent V., Dunoyer P., Genschik P., Ritzenthaler C. (2021). Immunocapture of dsRNA-bound proteins provides insight into Tobacco rattle virus replication complexes and reveals Arabidopsis DRB2 to be a wide-spectrum antiviral effector. Plant Cell 33, 3402-3420. doi: 10.1093/plcell/koab214.

Kelly A.G., Netzler N. E., White P. A. (2016). Ancient recombination events and the origins of hepatitis E virus. BMC Evol. Biol. 16, 210. doi: 10.1186/s12862-016-0785-y. 
Koonin E. V., Dolja V. V. (1993). Evolution and taxonomy of positive-strand RNA viruses: implications of comparative analysis of amino acid sequences. Crit. Rev. Biochem. Mol. Biol. 28, 375-430. doi: 10.3109/10409239309078440

Koonin E. V., Dolja V. V., Krupovic M., Varsani A., Wolf Y. I., Yutin N., Zerbini F. M., Kuhn J. H. (2020). Global organization and proposed megataxonomy of the virus world. Microbiol. Mol. Biol. Rev. 84, e00061. doi: 10.1128/MMBR.00061-19.

Kwon S-J., Choi G-S., Choi B., Seo J-K. (2018). Molecular characterization of an unusual new plant RNA virus reveals an evolutionary link between two different virus families. PLoS One 13, e0206382.https://doi.org/10.1371/journal.pone.0206382.

Lazareva E. A., Lezzhov A. A., Komarova T. V., Morozov S. Y., Heinlein M., Solovyev A. G. (2017). A novel block of plant virus movement genes. Mol. Plant Pathol. 18, 611-624. doi: $10.1111 / \mathrm{mpp} .12418$.

Lazareva E. A., Lezzhov A. A., Chergintsev D. A., Golyshev S. A., Dolja V. V., Morozov S. Y., Heinlein M., Solovyev A. G. (2021). Reticulon-like properties of a plant virus-encoded movement protein. New Phytol. 229, 1052-1066, doi: 10.1111/nph.16905.

Lehmann A. R. (2005). The role of SMC proteins in the responses to DNA damage. DNA Repair (Amst.) 4, 309-314. doi: 10.1016/j.dnarep.2004.07.009.

Liu S., Valencia-Jiménez A., Darlington M., Vélez A. M., Bonning B. C. (2020). Diabrotica undecimpunctata virus 2, a Novel Small RNA Virus Discovered from Southern Corn Rootworm, Diabrotica undecimpunctata howardi Barber (Coleoptera: Chrysomelidae). Microbiol. Resour. Announc. 9, e00380-20. doi: 10.1128/MRA.00380-20.

Miras M., Miller W. A., Truniger V., Aranda M. A. (2017). Non-canonical Translation in Plant RNA Viruses. Front. Plant Sci. 8, 494. doi: 10.3389/fpls.2017.00494.

Morozov S. Y., Solovyev A. G. (2003). Triple gene block: modular design of a multifunctional machine for plant virus movement. J. Gen. Virol. 84, 1351-1366. doi: 10.1099/vir.0.18922-0

Morozov, S. Y., Solovyev, A. G. (2015). Phylogenetic relationship of some 'accessory' helicases of plant positive-stranded RNAviruses: toward understanding the evolution of triple gene block. Front.Microbiol. 6, 508. doi: 10.3389/fmicb.2015.00508

Morozov S. Y., Solovyev A. G. (2020) Small hydrophobic viral proteins involved in intercellular movement of diverse plant virus genomes. AIMS Microbiol. 6, 305-329. doi: 10.3934/microbiol.2020019.

Niehl A., Liebe S., Varrelmann M., Koenig R. (2020) Benyviruses (Benyviridae). Reference Module in Life Sciences doi: 10.1016/B978-0-12-809633-8.21298-3.

Picarelli M.A.S.C., Forgia M., Rivas E. B., Nerva L., Chiapello M., Turina M., Colariccio A. (2019). Extreme Diversity of Mycoviruses Present in Isolates of Rhizoctonia solani AG2-2 LP From Zoysia japonica From Brazil. Front. Cell Infect. Microbiol. 9, 244. doi: 10.3389/fcimb.2019.00244. 
544 Pohlmann T., Baumann S., Haag C., Albrecht M., Feldbrügge M. (2015). A FYVE zinc finger domain protein specifically links mRNA transport to endosome trafficking. Elife 4, e06041. doi: 10.7554/eLife.06041.

Rodamilans B., Shan H., Pasin F., García J.A. (2018). Plant Viral Proteases: Beyond the Role of Peptide Cutters. Front. Plant Sci. 9, 666. doi: 10.3389/fpls.2018.00666.

Rozanov M. N., Koonin E. V., Gorbalenya A.E. (1992). Conservation of the Putative Rna Viruses. J Gen Virol. 73, 2129- 2134. doi: 10.1099/0022-1317-73-8-2129.

Saito,M., Kiguchi,T., Kusume,T. and Tamada,T. (1996) Complete nucleotide sequence of the Japanese isolate $S$ of beet necrotic yellow vein virus RNA and comparison with European isolates. Arch. Virol. 141, 2163-2175. doi: 10.1007/BF01718223.

Schön M. E., Zlatogursky V. V., Singh R. P., Poirier C., Wilken S., Mathur V., Strassert J. F. H., Pinhassi J., Worden A. Z., Keeling P. J., Ettema T. J. G., Wideman J. G., Burki F. (2021). Single cell genomics reveals plastid-lacking Picozoa are close relatives of red algae. Nat. Commun. 12, 6651. doi: 10.1038/s41467-021-26918-0.

Shi M., Lin X-D., Tian J-H., et al. (2016). Redefining the invertebrate RNA virosphere. Nature 540, 539-543. doi: 10.1038/nature20167.

Simm D., Hatje K., Waack S., Kollmar M. (2021) Critical assessment of coiled-coil predictions based on protein structure data. Sci. Rep. 11, 12439. doi: 10.1038/s41598-02191886-w.

Solovyev A.G., Makarov V. V. (2016). Helical capsids of plant viruses: architecture with structural lability. J. Gen. Virol. 97, 1739-1754. doi: 10.1099/jgv.0.000524.

Solovyev A. G., Morozov, S. Y. (2017) Non-replicative Integral Membrane Proteins Encoded by Plant Alpha-Like Viruses: Emergence of Diverse Orphan ORFs and Movement Protein Genes. Front. Plant. Sci. 8, 1820. doi: 10.3389/fpls.2017.01820.

Strassert J. F. H., Irisarri I., Williams T. A., Burki F. (2021). A molecular timescale for eukaryote evolution with implications for the origin of red algal-derived plastids. Nat. Commun. 12, 1879. doi: 10.1038/s41467-021-22044-z.

Tilsner, J., Linnik, O., Louveaux, M., Roberts, I. M., Chapman, S. N., and Oparka, K. J. (2013). Replication and trafficking of a plant virus are coupled at the entrances of plasmodesmata. J. Cell Biol. 201, 981-995. doi: 10.1083/jcb.201304003

Vakirlis N., Acar O., Hsu B., Castilho Coelho N., Van Oss S. B., Wacholder A., MedetgulErnar K., Bowman R.W. 2nd, Hines C. P., Iannotta J., Parikh S. B., McLysaght A., Camacho C. J., O'Donnell A. F., Ideker T., Carvunis A. R. (2020). De novo emergence of adaptive membrane proteins from thymine-rich genomic sequences. Nat. Commun. 11, 781. doi: 
592 Verchot-Lubicz, J., Torrance, L., Solovyev, A.G., Morozov, S.Y., Jackson, A.O., and Gilmer,

593 D. (2010). Varied movement strategies employed by triple gene block-encoding viruses. Mol.

594 Plant-Microbe Interact. 23, 1231-1247. doi: 10.1094/MPMI-04-10-0086.

595

596 Vlok, M., Gibbs, A. J., and Suttle, C. A. (2019). Metagenomes of a Freshwater Charavirus

597 from British Columbia Provide a Window into Ancient Lineages of Viruses. Viruses 11, 299.

598 doi: 10.3390/v11030299.

599

600 Zhu J. Z., Zhu H. J., Gao B. D., Zhou Q., Zhong J. (2018) Diverse, Novel Mycoviruses From

601 the Virome of a Hypovirulent Sclerotium rolfsii Strain. Front. Plant Sci. 9, 1738. doi:

$602 \quad 10.3389 /$ fpls.2018.01738.

603

604

605

606

607

608

609

610

611

612

613

614

615

616

617

618

619

620

621

622

623

624 


\section{FIGURES AND LEGENDS}

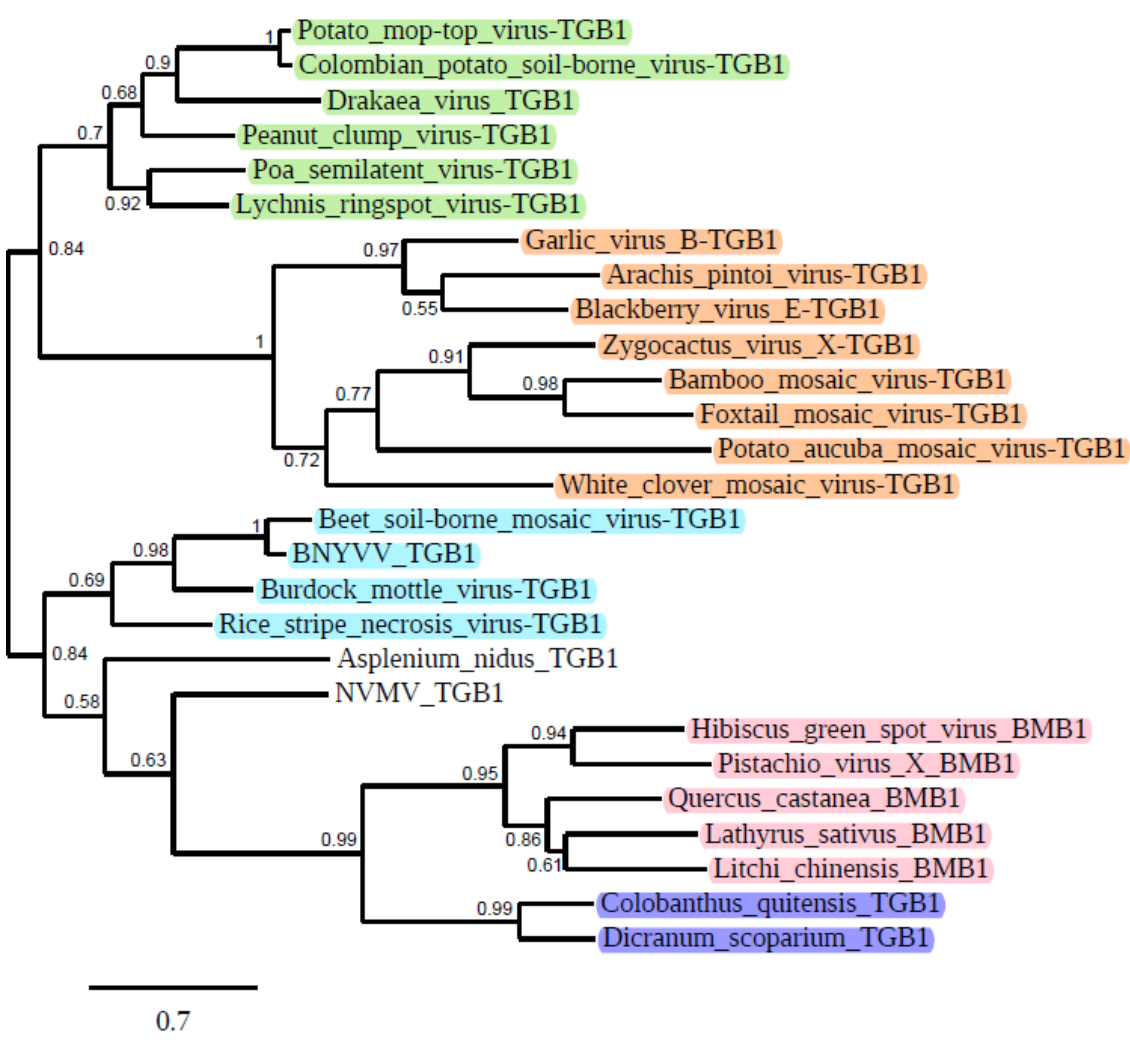

Fig. 1. Phylogenetic analysis of the helicase domains derived from the aligned deduced

628 amino acid sequences of the proteins encoded by TGBs and BMBs. The phylogenetic

629 unrooted tree was constructed using the maximum likelihood method based on the amino

630 acid sequence alignments (http://www.phylogeny.fr/simple_phylogeny.cgi). The bootstrap

631 values obtained with 1000 replicates are indicated on the branches, and branch lengths

632 correspond to the branch line's genetic distances. The genetic distance is shown by the scale

633 bar at the lower left. BNYVV - beet necrotic yellow vein virus; NVMV - Nicotiana velutina

634 mosaic virus. Hordei-like TGB1 helicases are in green, potex-like helicases - in brown,

635 benyvirus TGB1 helicases are in blue, BMB1 helicases found two viruses and three VLRAs

636 (Q. castanea, L. sativus and L. chinesis) are in pink, TCMB helicases found in the

637 corresponding VLRAs (C. quitensis and D. scoparium) are in dark blue.

638 A
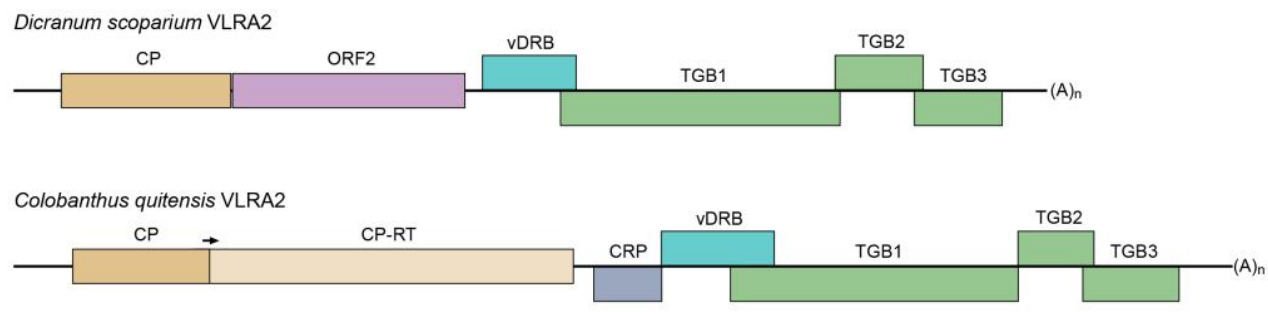
640 B

641

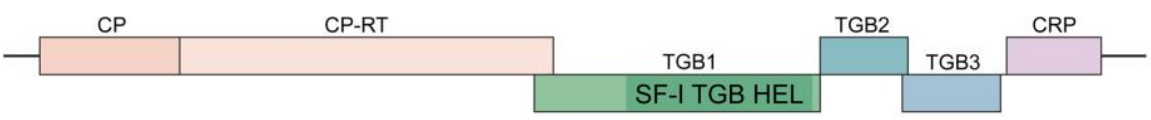

642 Fig. 2. Comparison of gene organization of RNA2 genomic components encoding

643 multicomponent cell-to-cell transport systems in D.scoparium and C.quitensis VLRAs (A)

644 and Beet necrotic yellow vein virus (B). Genes are shown as boxes with the names of the

645 encoded proteins. Genes of proteins potentially involved in cell-to-cell movement (TGB and

646 vDRB) are shown in green, dark green, light green and blue-green. Genes encoding small

647 hydrophobic proteins are shown in blue. Replicative genes are shown in yellow. Arrows

648 indicate read-through codons in CP-RT proteins. CRP - cysteine-rich protein, CP-RT - coat

649 protein read-through protein.

650

651

A

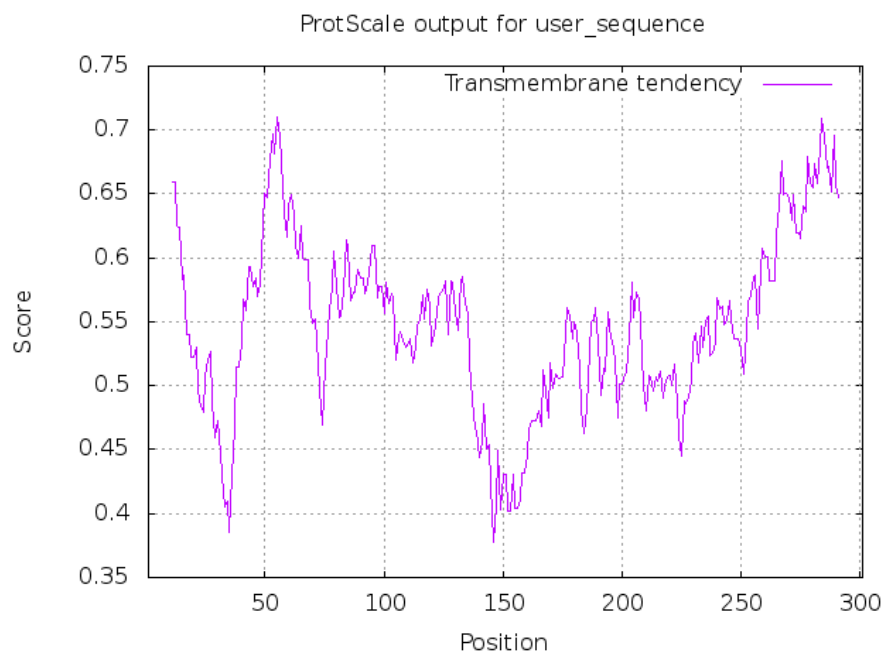

652

653

B

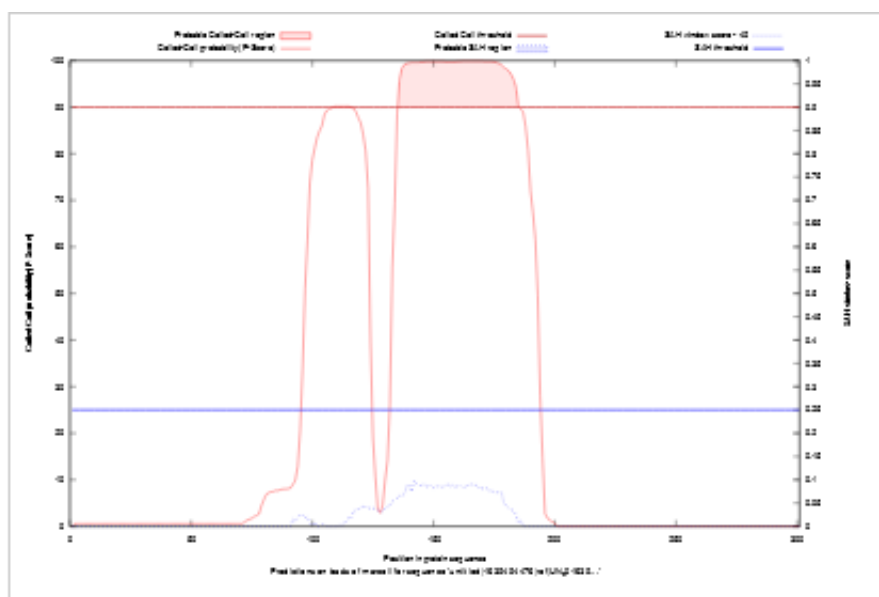

654 
655 Fig. 3. (A) Prediction of hydrophobic membrane-bound regions (https://web.expasy.org/ protscale/) and (B) coiled-coil segments (above red cut-off line) (https://waggawagga. motorprotein.de/) in ORF2 protein of Ds-VLRA2.

Fig. 4. Multiple sequence alignment of the dsRNA-binding centers of proteins HYL1, DRB4

DSORF3-RNILQELTQAKGGLLPVYFTYSYLAADGGICWGSSVSAFGIT-ERALNYKNKKVAEC
CqORF 4-KSALQVQTQRAYEDLPIYTSRRVGNLWFSRVDCYLGSAYGVA------GRKKVADC
AtDRB4-KNLLQEIAQKESSLLPFYATATSGPSHAPTFT-STVEFAGKV-FSGEEAKTKKLAEM
AtHYL1-KSRLQEYAQKYKLPTPVYEIVKEGPSHKSLFQ-STVILDGVRYNSLPGFFNRKAAEQ
AtDRB5-KNLLQETAHRAGLDLPMYTSVRSGSHFPGFS-CTVELAGMT-FTGESAKTKKQAEK
CPDRBL-KNLLQETAQRAGVSLPVYATTRSGPGHLPVFT-CTVEVASMT-FNGEAAKTKKQAEK
PPDRB2-KNLLQETAQRAGVSLPVYATRSGPGHLPVFT-CTVEVASMT-FSGEAAKTKKQAEA
SmDRBL-KNLLQETAQRAGVPLPIYTTVRSGPGHLPVFT-CTVGVGGMI-FTGEAAKTKKQAEA
MPDRBL-KNLLQETAQRAGVSLPVYTTTRSGPGHLPVFT-CQVELAGMK-FDGEAAKTKKQAEK
CbDRBL-KNLLQETSQRAGVALPVYHAMRMGPDHQPVYS-ASVEVAGMR-FYGQCAKTKKQAEK
NmDRBL-KNLLQETSQRAGVPLPVYHAMRMGPDHQPVYS-ASVEVAGMR-FYGQCAKTKKQAEK
SPDRBL-KNLLQETTQRAGIPLPIYITTRMGPDHLPVYS-SSVEMAGMR-FYGESAKTKKQAEK
and DRB5 from $A$. thaliana with vDRB proteins of $D$. scoparium (DsORF3) and $C$. quitensis (CqORF4) as well as DRB-like proteins of moss Ceratodon purpureus (CpDRBL accession KAG0625911), moss Physcomitrium patens (PpDRB2 - XP_024393530), lycophyte Selaginella moellendorffii (SmDRBL - EFJ14280), liverwort Marchantia polymorpha (MpDRBL - PTQ26790), charophyte algae Chara braunii (CbDRBL GGXX01036972), charophyte algae Nitella mirabilis (NmDRBL - JV799478), charophyte algae Spirogyra pratensis (SpDRBL - GFWN01008525).

681

682

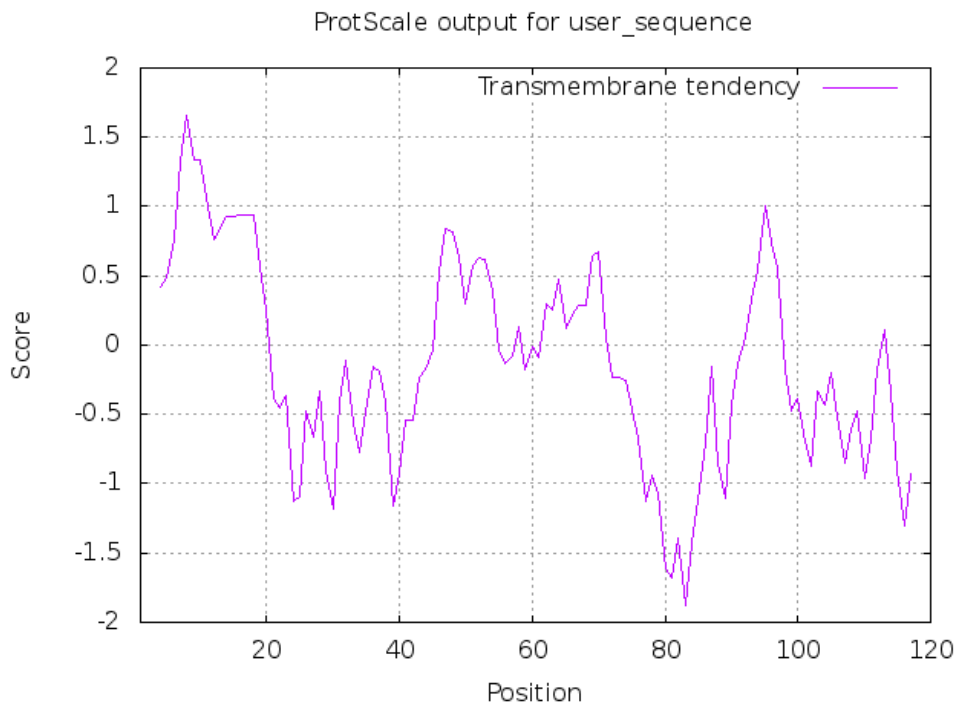

684 


\section{C. quitensis}

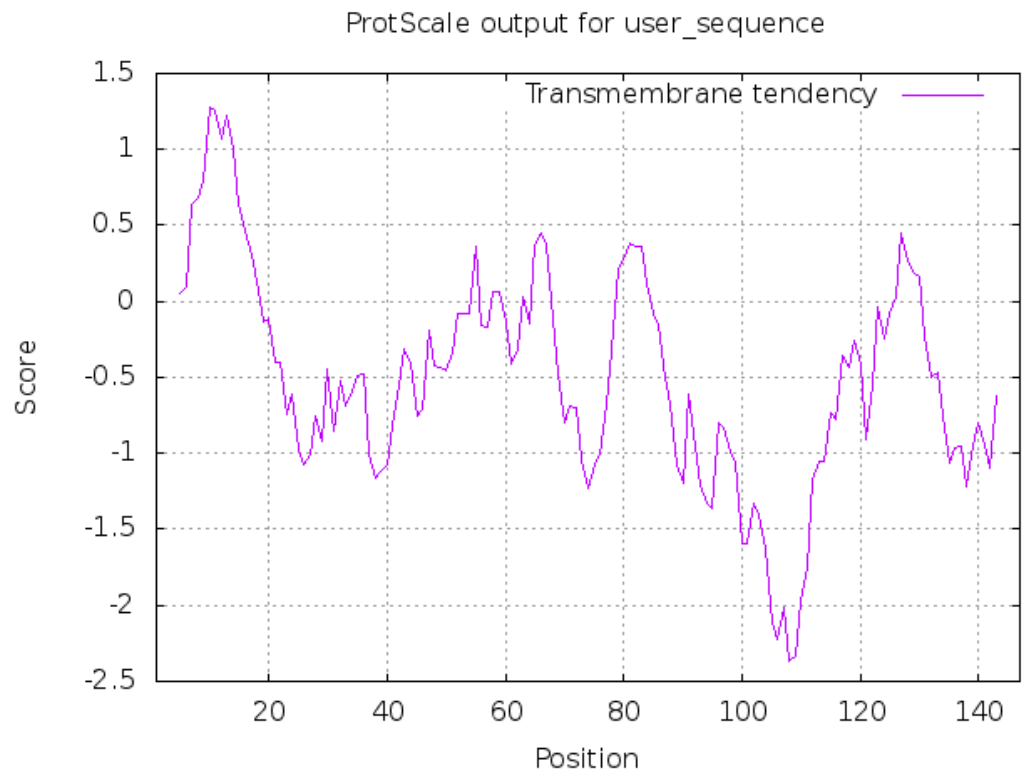

687

688 Fig. 5. Prediction of hydrophobic membrane-bound regions (https://web.expasy.org/ 689 protscale/) in vDRB proteins of D. scoparium (DsORF3) and C. quitensis (CqORF4).

690 Membrane-bound protein segments are above 0.8 cutoff line.
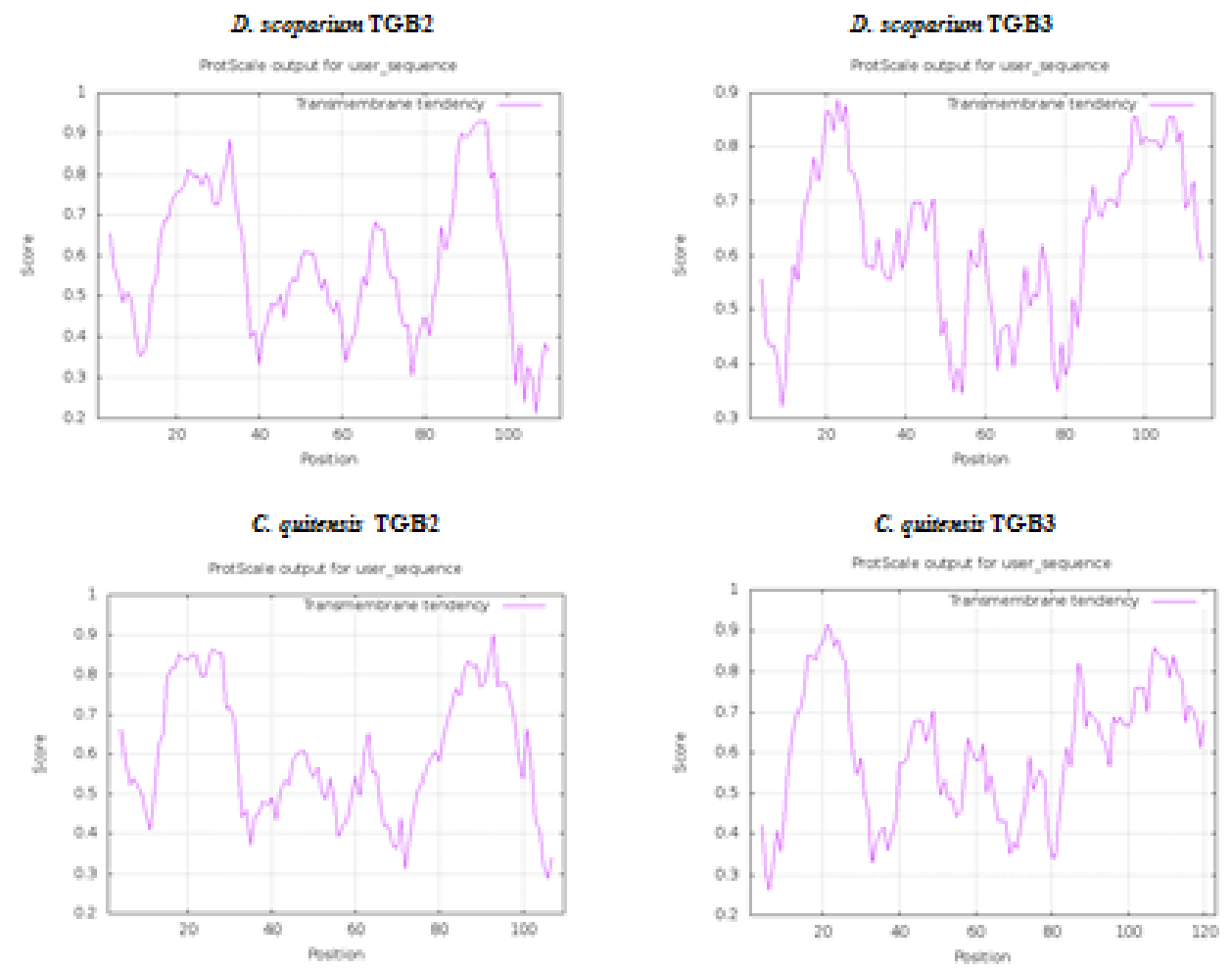

691

692 Fig. 6. Prediction of hydrophobic membrane-bound regions (https://web.expasy.org/

693 protscale/) in TGB-like proteins of D. scoparium and C. quitensis VLRAs. 
694 A

695

696

697

MGDRVVKLIEKREARLLEKERARNLKRFRIVEVEKGVWYQLEEGECFCSKSIHKHCARKCGEPTDGYCVMCSCELRAEQAYRTRNERK

B

698

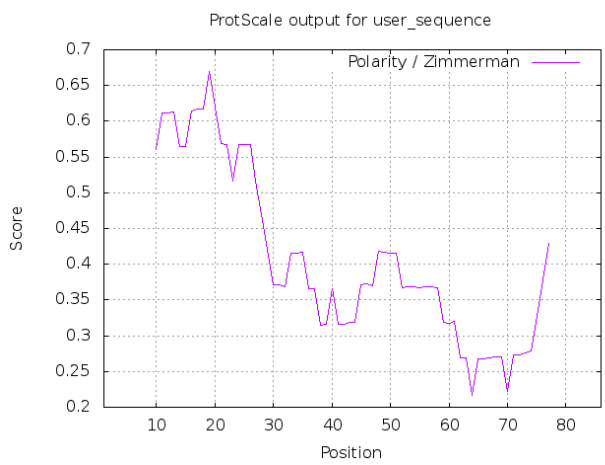

699 Fig. 7. (A) Amino acid sequence of an ORF3 protein encoded by Cq-VLRA2. Positively

700 charged residues are shown in red, negatively charged - in blue, cysteines - in yellow.

701 Putative zinc finger motif-containing module is underlined. (B) Polarity plot of ORF3 protein

702 (https://web.expasy.org/protscale/).

703

704

705

706

A

707

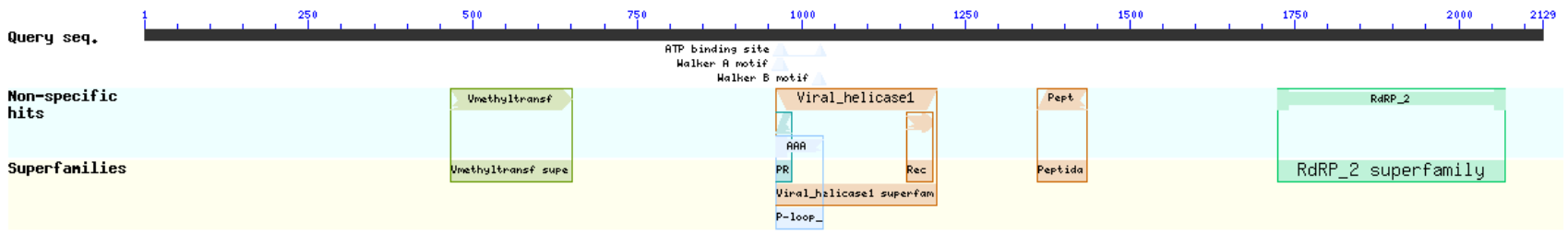

708

709

710

B

711

713

\section{RNA1} CTATTTGAGCGACAACAGTATCCGAGCT-AGACTCGTAAAGGTCTGAAGTGGCTCTTTTAGCAAGTATGATTCCCGAATG-AAAGGGTGTTAGTTTATTGCTGCTCTGTAGATAGAGTTT (A) n
CTATTTGA-TGA-GACAGTATCCGAGCAAAGACTCGTAAAGGTCTGAATCGTC--AAACGCGATGCGTTTCCTGTATGAAAAGGGAAC--GATTATTGCAACTCTGTAGATAGAGTTT (A) n RNA2

716

717 Fig. 8. (A) The predicted organization of ORF1 protein of Ds-VLRA1 (NCBI formate)

718 containing four conserved domains: a viral methyltransferase domain (Vmethyltransf, amino

719 acid positions 440-625); a viral helicase 1 domain (amino acid positions 939-1179); papain-

720 like proteinase domain (Pept, positions 1333-1408), and RdRp core motif (RdRP 2

721 superfamily, amino acid positions 1698-2045). (B) Nucleotide sequence alignment of the 3'- 
bioRxiv preprint doi: https://doi org/10.1101/2022.01 19.477018; this version posted January 21,2022 . The copyright holder for this preprint (which was not certified by peer review) is the author/funder, who has granted bioRxiv a license to display the preprint in perpetuity. It is made available under aCC-BY-NC-ND 4.0 International license. scoparium. Highly conserved RNA blocks are highlighted by yellow and green background.

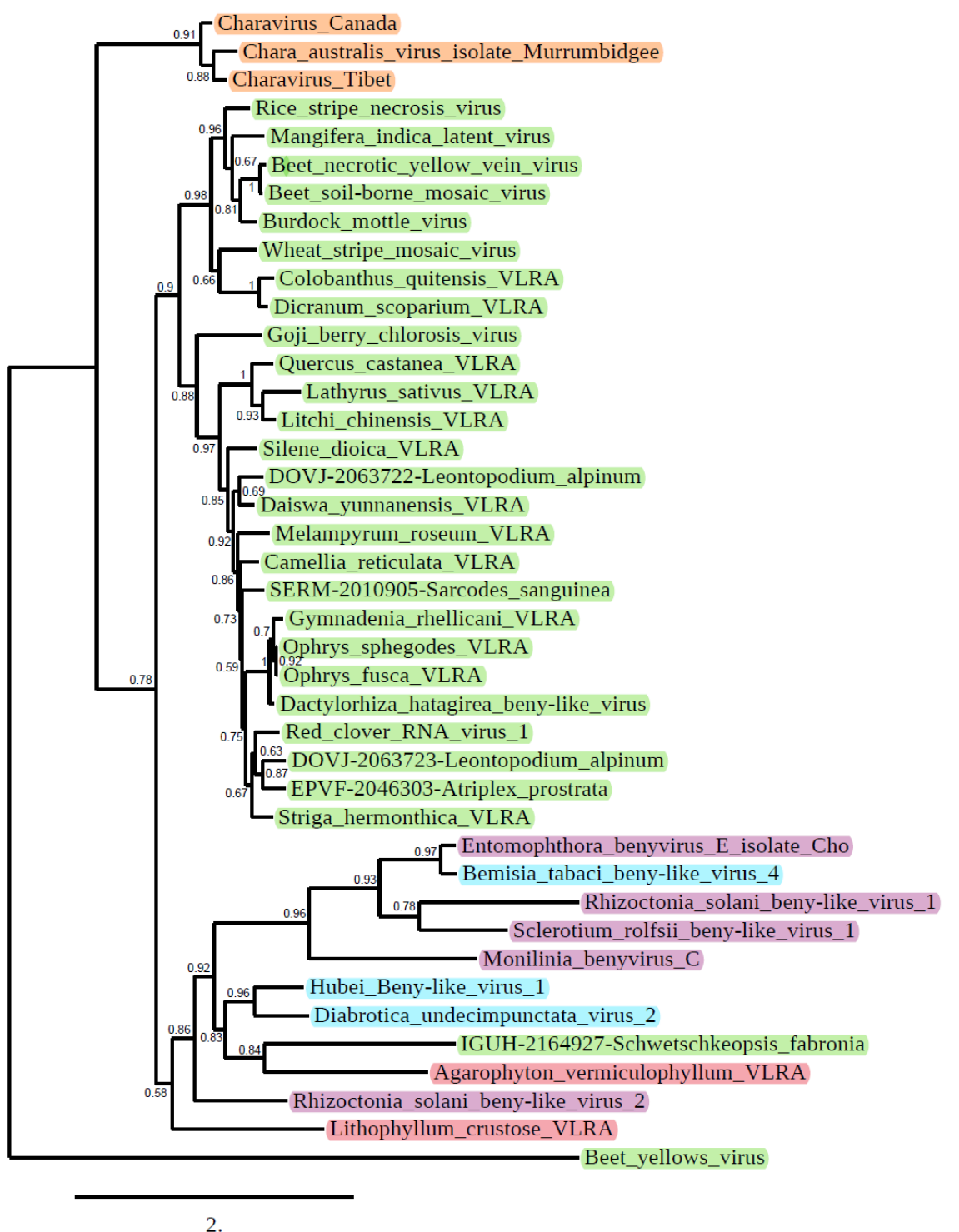

Fig. 9. Phylogenetic analysis of the conserved motifs of RdRp derived from the aligned deduced amino acid sequences of beny-like viruses and selected VLRAs. The phylogenetic tree was constructed using the maximum likelihood method at Phylogeny.fr. The beet yellows closterovirus RdRp was used as outgroup. The bootstrap values obtained with 1000 replicates are indicated on the branches, and branch lengths correspond to the branch line's genetic distances. The genetic distance is shown by the scale bar at the lower left. Charaviruses are shown in brown, plant viruses are in green, fungal viruses are in pink, arthropod viruses are in blue, red algae viruses are in rose. 


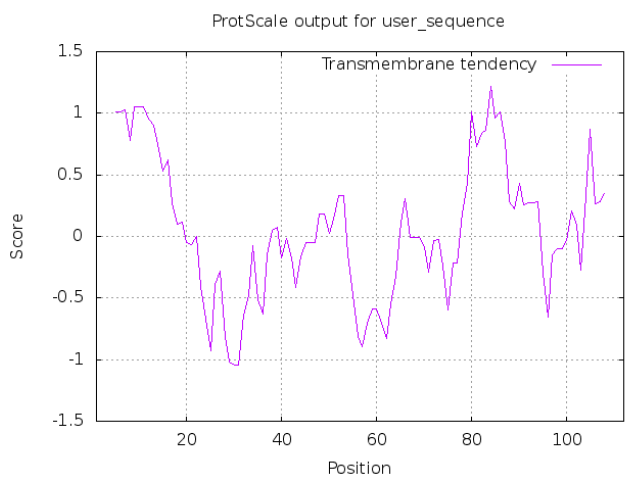

737 B

738

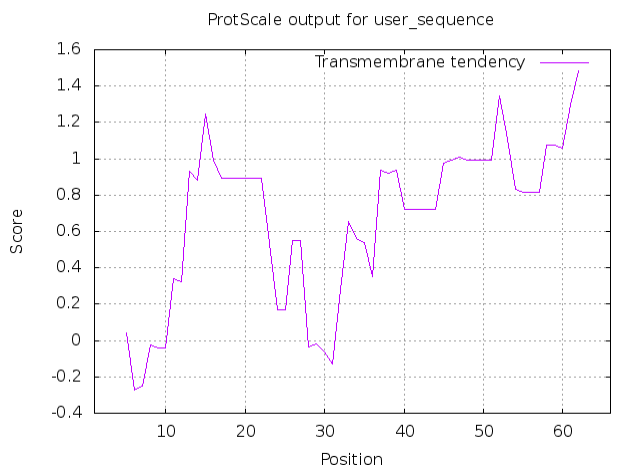

739 C

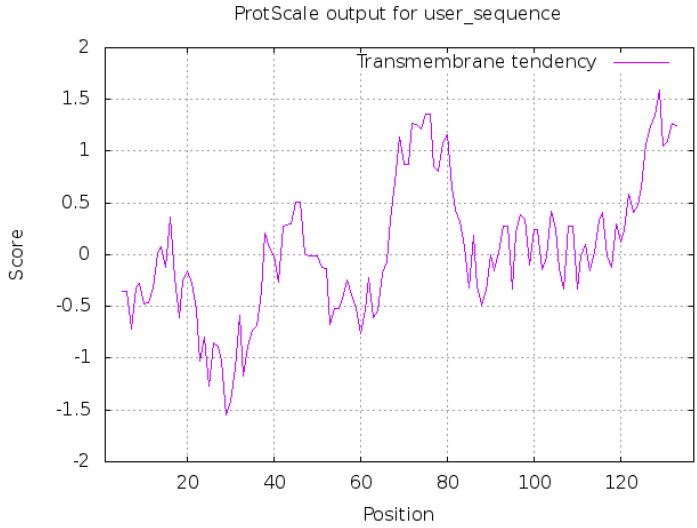

$\mathrm{C}$

741 Fig. 10. Prediction of hydrophobic membrane-bound regions (https://web.expasy.org/

742 protscale/) in p2 (A) and p3 (B) “orphan” proteins of Red clover RNA virus 1 (accession

743 MG596242) as well as ORF2 protein (C) of Dactylorhiza hatagirea beny-like virus (accession

744 BK013327). Membrane-bound protein segments are above 0.8 cutoff line. 


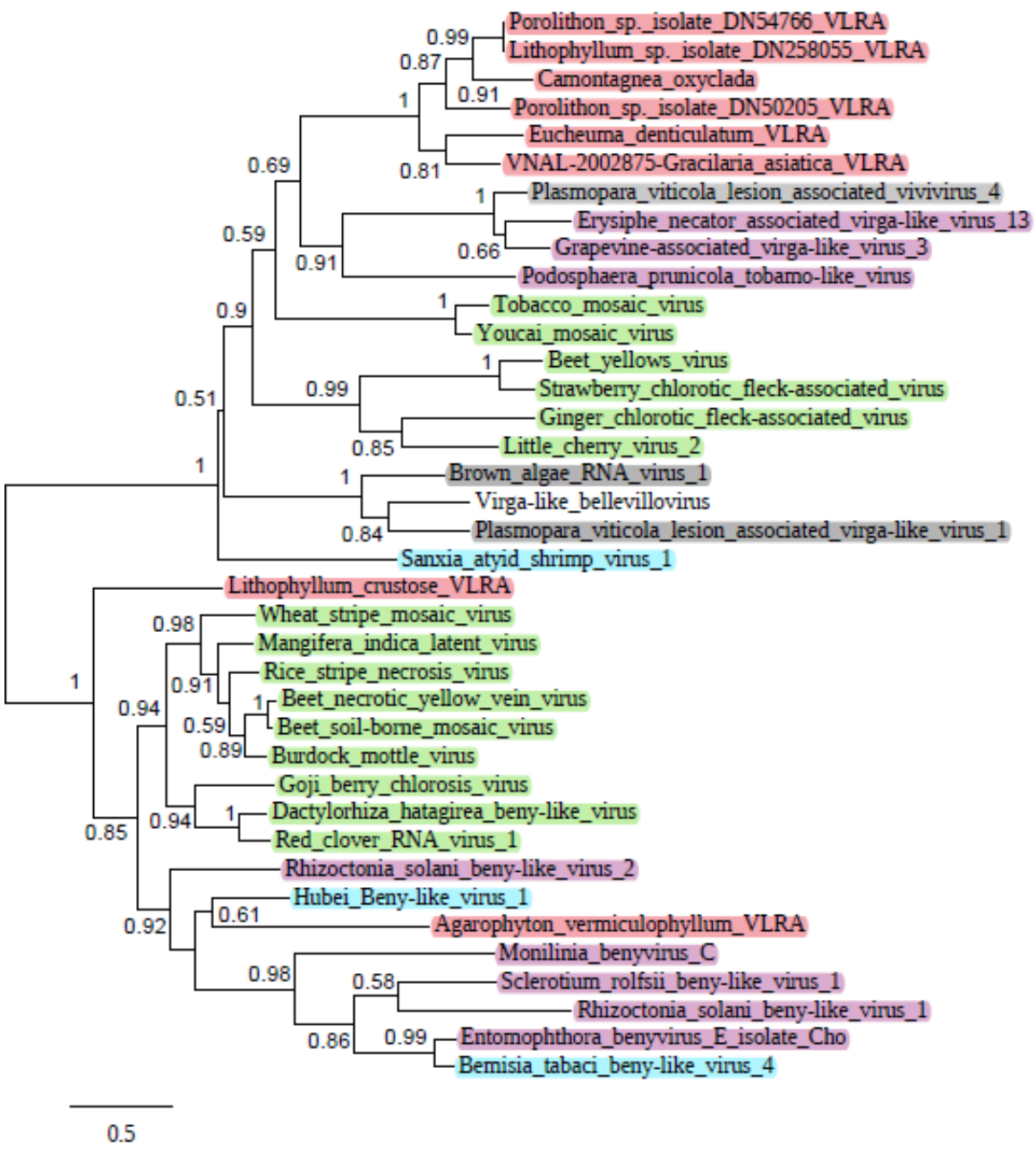

Fig. 11. Phylogenetic analysis of the conserved motifs of RdRp derived from the aligned

749 deduced amino acid sequences of selected beny-like replicative proteins (bottom branch),

750 virga-like replicative proteins (upper branch) and red algae VLRAs. The unrooted

751 phylogenetic tree was constructed using the maximum likelihood method at Phylogeny.fr.

752 The bootstrap values obtained with 1000 replicates are indicated on the branches, and branch

753 lengths correspond to the branch line's genetic distances. The genetic distance is shown by

754 the scale bar at the lower left. Viruses of Stramenopiles are shown as shaded, plant viruses are in green, fungal viruses are in pink, arthropod viruses are in blue, red algae viruses are in rose. 